\title{
Reappraisal of the aetiology and prognostic factors of severe acute respiratory failure in HIV patients
}

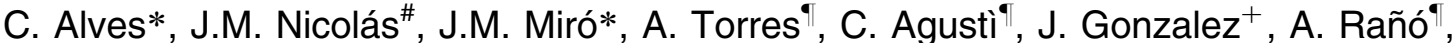 \\ N. Benito*, A. Moreno*, F. Garcì*, J. Millá\#, J.M. Gatell*
}

Reappraisal of the aetiology and prognostic factors of severe acute respiratory failure in HIV patients. C. Alves, J.M. Nicolás, J.M. Miró, A. Torres, C. Agustì, J. Gonzalez, A. Rañó, N. Benito, A. Moreno, F. Garcìa, J. Millá, J.M. Gatell. C) ERS Journals Ltd 2001.

ABSTRACT: The introduction of highly active antiretroviral therapy with protease inhibitors in 1996 has changed the morbidity and mortality of acquired immune deficiency syndrome patients. Therefore, the aetiologies and prognostic factors of human immunodeficiency virus (HIV)-infected patients with life-threatening respiratory failure requiring intensive care unit (ICU) admission need to be reassessed.

From 1993 to 1998 , we prospectively evaluated $57 \mathrm{HIV}$ patients (mean \pm SEM age $36.5 \pm 1.3 \mathrm{yrs}$ ) admitted to the ICU showing pulmonary infiltrates and acute respiratory failure.

A total of 21 and 30 patients were diagnosed as having Pneumocystis carinii and bacterial pneumonia, respectively, of whom 13 and eight died during their ICU stay $(p=0.01)$. Both groups of patients had similar age, Acute Physiology and Chronic Health Evaluation (APACHE) II score, and severity in respiratory failure. The number of cases with bacterial pneumonia admitted to ICU decreased after $1996(p=0.05)$. Logistic regression analysis showed that (APACHE) II score $>17$, serum albumin level $<25 \mathrm{~g} \cdot \mathrm{L}^{-1}$, and diagnosis of $P$. carinii pneumonia were the only factors at entry associated with ICU mortality $(p=0.02)$.

Patients with bacterial pneumonia are less frequently admitted to the intensive care unit after the introduction of highly active antiretroviral therapy with protease inhibitors in 1996. Compared to the previous series, it was observed that the few Pneumocystis carinii pneumonia patients that need intensive care still have a bad prognosis.

Eur Respir J 2001; 17: 87-93.

\author{
*Dept of Infectious Diseases Service, \\ ${ }^{\#}$ Medical and "Respiratory Intensive \\ Care Units, and ${ }^{+}$Microbiology \\ Laboratory Institut d'Investigacions \\ Biomëdiques August Pi i Sunyer Hos- \\ pital Clinic, Facultat de Medicina, \\ Universitat de Barcelona, Villarroel \\ 170, Barcelona, Spain.
}

Correspondence: A. Torres, Respiratory Intensive Care Unit, Servei de pneumologia, Institut clínic de pneumologia, i Cirurgia Toràcia, Hospital Clìnic, Villarroel 170, 08036, Barcelona, Spain.

Fax: 34934515272

Keywords: Bacterial pneumonia, HIV, Pneumocystis carinii, prognosis, respiratory failure

Received: March 162000

Accepted after revision August 22000

This work was supported by grants from SEIMC/API and Fundaciûn Maximo Soriano Gimènez.
Patients with human immunodeficiency virus (HIV) infection, and especially acquired immunodeficiency syndrome (AIDS) patients, may suffer from episodes of pulmonary infiltrates accompanied by severe respiratory failure during the course of their illness [1]. In the previous decade, Pneumocystis carinii pneumonia was the main cause of severe respiratory failure in HIV patients admitted to the Hospital clinic of Barcelona Medical and Respiratory intensive care units (ICU), and was associated with a poor outcome when mechanical ventilation was required [2]. The introduction of $P$. carinii prophylaxis in the clinical practice in the late 1980s, usually with cotrimoxazole, was the first step in reducing the incidence of $P$. carinii pneumonia, as well as other bacterial infections of the upper respiratory tract [3]. An earlier treatment against $P$. carinii and the systematic use of steroids as co-adjuvant therapy has also been responsible for a decrease in severe episodes of $P$. carinii pneumonia [4, 5]. However, a manifest reduction in the morbidity and mortality of AIDS patients was not observed until the introduction of highly active antiretroviral therapy (HAART) with protease inhibitors in 1996 [6]. The immunological reconstitution, increasing the numerical and functional CD4 cell profile, produced by HAART, confers host protection against opportunistic infections [7], leading to a potential decrease in $P$. carinii as well as bacterial pneumonia $[8,9]$. In some cases, this may result in a discontinuation in primary and secondary prophylaxis against $P$. carinii and other opportunistic infections [10].

The aim of the present study was therefore to reassess the aetiologies and prognostic factors of life-threatening respiratory failure in HIV patients requiring ICU admission. Patients admitted to the ICU from 19931998 were included in the study, taking into account the systematic use of $P$. carinii prophylaxis since the late 1980s and the introduction of HAART in 1996. Moreover, we have compared the current findings with those observed from 1985-1992 [2].

\section{Patients and methods}

\section{Patients}

All HIV patients showing pulmonary infiltrates and acute respiratory failure (arterial oxygen tension $\left(\mathrm{Pa}, \mathrm{O}_{2}\right)$ 
$<7 \mathrm{kPa}$ breathing room air or $\mathrm{Pa}_{2} \mathrm{O}_{2} /$ inspiratory oxygen fraction $\left(F \mathrm{I}, \mathrm{O}_{2}\right)$ ratio $\left.<33 \mathrm{kPa}\right)$ admitted to the Medical and Respiratory ICUs of the Hospital Clinic of Barcelona from 1993-1998 were included. Sixty patients fulfilled inclusion criteria, although three subjects admitted for postoperative recovery were excluded from the study. Twenty-eight patients came directly from the Emergency Room, whereas twenty-nine patients had first been admitted to the Infectious Disease Ward with respiratory symptoms, and were thereafter transferred to the ICU because of impending respiratory failure. Patients were managed in the ICU by continuous positive airway pressure, Venturi masks, or masks with a reservoir, before invasive mechanical ventilation was applied.

Out of 57 patients, $47(82 \%)$ fulfilled criteria for AIDS [11]. HIV infection was diagnosed in eight patients at the time of hospital admission. Nineteen out of 47 eligible subjects were receiving primary prophylaxis against $P$. carinii with cotrimoxazole. Twenty-five patients were on antiretroviral therapy before admission, eight of whom were on triple therapy with two nucleoside analogue transcriptase inverse inhibitors plus one protease inhibitor (HAART). Protease inhibitors were introduced in Spain in 1996, and as part of routine treatment in all HIV patients controlled by the HIV-outpatient clinic after February 1996. Antiretroviral therapy was discontinued while the patients remained in the ICU.

Hospital therapy for $P$. carinii included i.v. cotrimoxazole, with the maximum dosage for trimethoprim being $20 \mathrm{mg} \cdot \mathrm{kg}^{-1}$ q.d., and for sulphamethoxazole 100 $\mathrm{mg} \cdot \mathrm{kg}^{-1}$ divided in four doses; or i.v. pentamidine ( $4 \mathrm{mg} \cdot \mathrm{kg}^{-1}$ once daily) according to the decision of the attending physician. Corticosteroids were routinely administered either on suspicion or diagnosis of $P$. carinii pneumonia in 48 patients at a dosage of methylprednisolone at $1 \mathrm{mg} \cdot \mathrm{kg}^{-1}$ q.d. for 5 days, with the dosage later being gradually reduced. Antibiotic therapy against community-acquired bacterial pneumonia included a third generation cephalosporin (ceftriaxone or cefotaxime) plus a macrolide. The duration and type of antibiotic therapy against tuberculosis and other pulmonary pathogens was determined according to the recommended regimen [12].

\section{Clinical and laboratory assessment}

Epidemiological data and type of antiretroviral therapy were recorded. Chest radiograph examination and ventilatory parameters were recorded on hospital (retrospective) and ICU entry, and after the institution of mechanical ventilation. The parameters included $\mathrm{pH}$, $P \mathrm{a}, \mathrm{O}_{2}, P \mathrm{a}, \mathrm{CO}_{2}, P \mathrm{a}, \mathrm{O}_{2} / F \mathrm{I}, \mathrm{O}_{2}$ ratio, and alveolar to arterial difference in oxygen tension $\left(P \mathrm{~A}-\mathrm{a}, \mathrm{O}_{2}\right)$. The presence of acute respiratory distress syndrome (ARDS) was considered according to the European Consensus score [13], these patients showing a Murrays score of $\geqslant 2.5[14]$.

Leukocyte and lymphocyte counts, recent CD4 count (from 40 routinely followed patients), serum creatinine, total cholesterol, total proteins, albumin and serum lactate dehydrogenase (LDH) were recorded upon ICU admission. The Acute Physiology and Chronic Health Evaluation score (APACHE II) [15] was calculated on hospital and ICU admission. The presence of systemic inflammatory response syndrome [16], and the sepsisorgan failure assessment [17] and multiple organ dysfunction syndrome scores [18] were recorded upon ICU admission. Bacterial pneumonia was classified as community-acquired or nosocomial according to the American Thoracic Society criteria [19].

\section{Microbiological methods}

Bronchoalveolar lavage (BAL) together with protected specimen brush (PSB) samples (BFW 1.0/70/90; Meditech Inc., Water-Town, MA, USA) were retrieved by means of a fibreoptic bronchoscope (Olympus BFT3R, New Hyde Park, NY, USA) exclusively used for HIV-infected patients. As part of a routine medical assessment, BAL with PSB was systematically performed in patients with interstitial pulmonary infiltrates and in those mechanically ventilated who did not promptly respond to antibiotic therapy $(80 \%)$. Eleven patients with lobar infiltrates or not requiring mechanical ventilation, four of whom were finally diagnosed with pulmonary tuberculosis based on the presence of Mycobacterium tuberculosis in the sputum, did not undergo bronchoscopic microbiological studies.

BAL and PSB microbiological studies and sample processing were performed using standard methods, and thresholds for quantitative cultures of BAL $10^{4}$ colony forming units $(\mathrm{cfu}) \cdot \mathrm{mL}^{-1}$ and PSB $10^{3} \mathrm{cfu} \cdot \mathrm{mL}^{-1}$ were applied, as described in detail previously [2]. In brief, serial dilutions of BAL and PSB samples were prepared in normal saline to obtain final concentrations of $10^{-1}, 10^{-2}$, and $10^{-3}$. Half of the specimen amount was inoculated into blood-agar, Wilkins-Chalgren, chocolate-agar, buffered charcoal yeast extract (BCYE)- $\alpha$, and fungal media. The other half of the fluid obtained was centrifuged and the cell pellet was resuspended in phosphate-buffer solution. Smears were obtained by cytocentrifugation and were stained by the Papanicolau, Ziehl-Nielsen, Giemsa, periodic acid-Schiff (PAS), haematoxylin and eosin, Perls' and Grocott methenamine-silver methods. Staining for Legionella pneumophila was performed using the direct fluorescent antibody technique. Serological tests for respiratory virus (influenza, parainfluenza, adenovirus, respiratory syncytial virus), Mycoplasma pneumoniae, and $L$. pneumophila were also performed. The diagnosis of cytomegalovirus was considered only if cytopathic changes were found in BAL samples.

\section{Statistical analysis}

Standard statistical methods from the statistical package for the social sciences (SPSS) Statistical Analysis System V-9.0 (SPSS, Chicago, IL, USA) were used. Differences between groups were analysed using Chi-squared, Fisher's exact, Mann-Whitney U-, and two-tailed t-tests. In order to identify factors associated with risk of death in the different groups, univariate and forward-selection multivariate logistic 
regression analysis were performed. Variables were categorized according to the population median and using enter criteria of $\mathrm{p}=0.05$ and a removal criteria of $p=0.10)$. Survival estimates of the different groups were compared by the Kaplan-Meier method (log-rank analysis) [20]. All variables are expressed as mean \pm SEM and significance was set at $\mathrm{p}=0.05$.

\section{Results}

\section{Clinical and microbiological data}

The main characteristics of the population studied are summarized in table 1. After 1996, only eight $(33 \%)$ of the patients were on HAART treatment, compared to about $80 \%$ of the HIV population controlled in the outpatient clinic. On ICU entry, chest radiograph disclosed bilateral interstitial pulmonary infiltrates in 35 patients, lobar consolidation in 16 subjects (half of them unilateral), and bilateral mixed infiltrates in the remaining six patients. On inclusion, 51 patients exhibited a $P \mathrm{a}, \mathrm{O}_{2} / F \mathrm{I}, \mathrm{O}_{2}$ ratio lower than $33 \mathrm{kPa}$ and the remaining six subjects had $\mathrm{Pa}_{2} \mathrm{O}_{2}<7 \mathrm{kPa}$ breathing room air (table 1). The patients included from the Infectious Disease ward had been admitted to the ICU after a mean hospital stay of 10.5 days (range 2-32 days), and corresponded to a group of patients with a delayed diagnosis and/or poor response to conventional antimicrobial therapy. Obviously, these patients had significantly better pulmonary and illness scores on hospital admission (data not shown). Notwithstanding, when finally admitted to the ICU, patients from the Infectious Disease ward were in a poorer condition than subjects from the Emergency room (APACHE II score (17.9 \pm 0.8 versus $15.2 \pm 0.7$, $\mathrm{p}=0.02) ; P \mathrm{a}, \mathrm{O}_{2} / F \mathrm{I}, \mathrm{O}_{2}$ ratio $(18.2 \pm 1.9$ versus $26.1 \pm 3.2$ $\mathrm{kPa}, \mathrm{p}=0.04)$ ).

The micro-organisms isolated and the diagnostic procedures used are shown in table 2. Twenty-one patients had $P$. carinii on the BAL, six with concurrent bacterial infections. These patients represented $6.8 \%$ of the $307 P$. carinii pneumonia episodes diagnosed in our Hospital over the same period (1993-1998). As seen in figure 1, episodes of $P$. carinii pneumonia admitted to hospital markedly decreased after the introduction of HAART, although $2-5$ cases of $P$. carinii pneumonia per year still required ICU admission. Most of these cases corresponded to subjects with undetected HIV infection, or who were not compliant with $P$. carinii prophylaxis and antiretroviral therapy. On the other hand, four patients were diagnosed with pulmonary tuberculosis and 30 with bacterial pneumonia, with microbiological confirmation in $40 \%$ of the latter (table 2). Bacterial pneumonia was considered community-acquired in 23 cases $(77 \%)$ and nosocomial in 7 patients $(23 \%)$. The remaining cases corresponded to one patient with endocarditis and pulmonary infiltrates and another subject with bronchopulmonary Kaposi's sarcoma.

The next step was to compare the characteristics between $P$. carinii pneumonia (all patients documented

Table 1. - Main epidemiological data on intensive care unit (ICU) admission of the population studied, and characteristics of patients with Pneumocystis carinii compared with those with bacterial pneumonia

\begin{tabular}{|c|c|c|c|c|}
\hline & $\begin{array}{l}\text { All patients } \\
\mathrm{n}=57\end{array}$ & $\begin{array}{l}\text { P. carinii pneumonia } \\
\mathrm{n}=21\end{array}$ & $\begin{array}{l}\text { Bacterial pneumonia } \\
\qquad \mathrm{n}=30\end{array}$ & $\begin{array}{l}\text { Univariate } \\
\text { p-value }\end{array}$ \\
\hline Age yrs & $36.5 \pm 1.3$ & $39.6 \pm 2.3$ & $34.8 \pm 1.6$ & 0.10 \\
\hline $\operatorname{Sex}(\mathrm{M} / \mathrm{F})$ & $44 / 13$ & $16 / 5$ & $22 / 8$ & 0.81 \\
\hline Admission (before/after 1996) $\mathrm{n}$ & $33 / 24$ & $10 / 11$ & $21 / 9$ & 0.05 \\
\hline AIDS definition (A3, B3, C3) & $47(82)$ & $21(100)$ & $21(70)$ & 0.002 \\
\hline PCP prophylaxis* ( $\mathrm{n}=47$ eligible) & $19(39)$ & $10(47)$ & $7(23)$ & 0.08 \\
\hline Prior antiretroviral treatment & $25(43)$ & $10(47)$ & $13(43)$ & 0.76 \\
\hline HAART & $8(14)$ & 4 (19) & $3(10)$ & 0.42 \\
\hline Bilateral infiltrates & $49(85)$ & $21(100)$ & $24(80)$ & 0.03 \\
\hline MV requirement & $35(61)$ & $14(66)$ & $18(60)$ & 0.63 \\
\hline$P \mathrm{a}, \mathrm{O}_{2} / F \mathrm{I}, \mathrm{O}_{2} \mathrm{kPa}$ & $18.4 \pm 1.4$ & $16.9 \pm 1.6$ & $19.5 \pm 3.3$ & 0.32 \\
\hline$P A-a, O_{2} \mathrm{kPa}$ & $46.5 \pm 3.1$ & $55.2 \pm 4.6$ & $44.0 \pm 4.4$ & 0.09 \\
\hline APACHE II score & $16.6 \pm 0.6$ & $16.3 \pm 1.1$ & $16.7 \pm 0.8$ & 0.74 \\
\hline SIRS & $52(91)$ & $19(90)$ & $27(90)$ & 0.95 \\
\hline SOFA score & $6.8 \pm 0.2$ & $6.2 \pm 0.3$ & $7.2 \pm 0.2$ & 0.03 \\
\hline MODS score & $5.5 \pm 0.2$ & $5.0 \pm 0.2$ & $5.9 \pm 0.1$ & 0.05 \\
\hline Lymphocytes $10^{9} \cdot \mathrm{L}^{-1}$ & $1.01 \pm 0.09$ & $0.78 \pm 0.13$ & $1.0 \pm 0.28$ & 0.47 \\
\hline CD4 lymphocytes $10^{6} \cdot \mathrm{L}^{-1 \#}(\mathrm{n}=40)$ & $98 \pm 17$ & $29 \pm 8$ & $157 \pm 31$ & 0.001 \\
\hline Serum LDH IU $\cdot \mathrm{L}^{-1}$ & $970 \pm 91$ & $1075 \pm 151$ & $686 \pm 68$ & 0.03 \\
\hline Serum $\mathrm{LDH}>1,000 \mathrm{IU} \cdot \mathrm{L}^{-1}$ & $16(28)$ & $11(52)$ & $4(13)$ & 0.006 \\
\hline Cholesterol $\mathrm{mmol} \cdot \mathrm{L}^{-1}$ & $3.07 \pm 0.17$ & $3.74 \pm 0.29$ & $2.63 \pm 0.24$ & 0.007 \\
\hline Serum albumin $\mathrm{g} \cdot \mathrm{L}^{-1}$ & $27.6 \pm 0.8$ & $27.9 \pm 1.4$ & $27.3 \pm 1.2$ & 0.76 \\
\hline
\end{tabular}

Data are expressed as mean \pm SEM or $\mathrm{n}(\%)$, and refer to ICU admission unless indicated otherwise. p-values result from comparing the groups of Pneumocystis carinii and bacterial pneumonia (see Methods). HIV: human immunodeficiency virus; HAART: Highly active antiretroviral therapy; AIDS: Acquired immunodeficiency syndrome; PCP: Pneumocystis carinii pneumonia; $\mathrm{MV}$ : mechanical ventilation; $\mathrm{Pa}, \mathrm{O}_{2}$ : arterial oxygen tension; $F \mathrm{I}, \mathrm{O}_{2}$ : inspiratory oxygen fraction; $P \mathrm{~A}-\mathrm{a}, \mathrm{O}_{2}$ : alveolar to arterial difference in oxygen tension; APACHE II: acute physiology and chronic health evaluation score; SIRS: systemic inflammatory response syndrome; SOFA: sepsis-related organ failure assessment score; MODS: multiple organ dysfunction syndrome; LDH: lactate dehydrogenase; *: $n=47 ;{ }^{\#}: n=40$. 


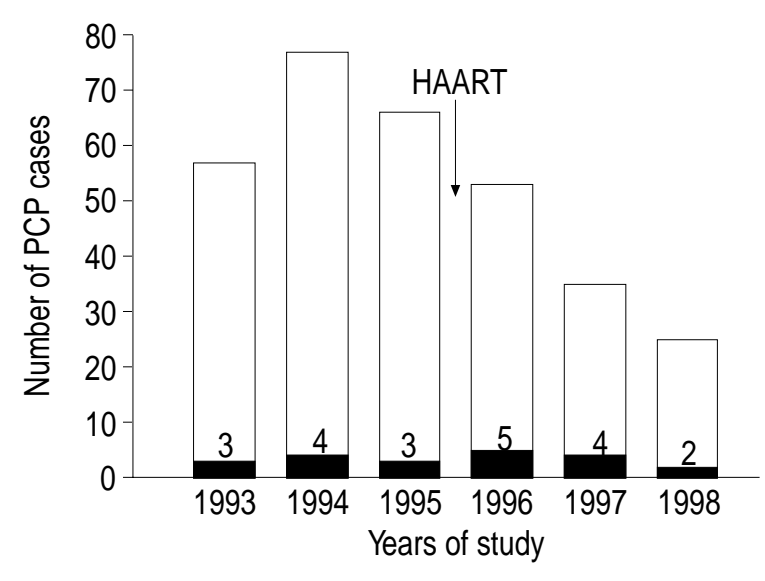

Fig. 1. - Episodes of Pneumocystis carinii pneumonia (PCP) admitted to hospital $\square$ and the intensive care unit (ICU) With the introduction of high antiretroviral therapy with protease inhibitors after 1996 there was a reduction in the amount of cases of $P$. carinii pneumonia. However, 2-5 patients $P$. carinii pneumonia per year still required ICU admission because of life-threatening respiratory failure.

microbiologically) and patients with bacterial pneumonia (pulmonary tuberculosis excluded), as shown in table 1. Age, APACHE II score, and severity of respiratory failure were similar in both groups of patients at ICU admission. Compared to subjects with bacterial pneumonia, patients with $P$. carinii pneumonia showed a worse immune status and had greater serum LDH concentrations than subjects with bacterial pneumonia. Curiously, similar to a previous series [2], serum cholesterol levels were significantly greater in patients with $P$. carini pneumonia. After 1996, a

Table 2. - Micro-organisms isolated from the patients

\begin{tabular}{lrc}
\hline & $\begin{array}{c}\text { Cases } \\
\mathrm{n}\end{array}$ & $\begin{array}{c}\text { Diagnostic } \\
\text { method }\end{array}$ \\
\hline P. carinii along & 15 & BAL \\
$P$. carinii + P. aeruginosa & 1 & BAL \\
P. carinii + Actinomyces Israelii & 1 & BAL \\
$P$. carinii + CMV & 1 & BAL \\
$P$. carinii + A. fumigatus + CMV & 1 & BAL \\
$P$. carinii + Enterobacter aerogenes & 1 & BAL \\
$P$. carinii + A. baumanii & 1 & BAL \\
S. pneumoniae along & 4 & BAL+BC \\
S. pneumoniae + E. faecalis & 1 & BAL \\
S. pneumoniae + H. influenzae & 1 & BAL \\
H. influenzae + Escherichia coli & 1 & BAL \\
H. influenzae + Varicella & 1 & BAL \\
Coagulase negative staphylococci & 1 & BAL \\
P. aeruginosa + S. maltophilia & 1 & BAL \\
E. faecalis + A. fumigatus & 1 & BAL \\
E. faecalis + Candida albicans & 1 & BAL+BC (both) \\
Mycobacterium tuberculosis & 4 & Sputum \\
BAL and PSB negative & 13 & - \\
Unknown and BAL done & 7 & - \\
\hline$P$. & & - \\
\hline
\end{tabular}

P. carinii: Pneumocystis carinii; P. aeruginosa: Pseudomonas aeruginosa; A. fumigatus: Aspergillus fumigatus; A. baumanii: Acinetobacter baumanii; S. pneumoniae: Streptococcus pneumoniae; E. faecalis: Enterococcus faecalis; H. influenzae: Haemophilus influenzae; S. maltophilia: Stenotrophomonas maltophilia; BAL: broncoalveolar lavage. PSB: protected specimen brush. BC: blood cultures. CMV: cytomegalovirus. significant decrease in the number of bacterial pneumonia admitted to ICU was observed. No differences were observed in severity in the patients with bacterial pneumonia admitted before and after 1996.

\section{Risk factors influencing intensive care unit outcome}

Twenty-three (40\%) HIV-infected patients died during their ICU stay, whereas $34(60 \%)$ cases were discharged alive. Thirteen patients died from $P$. carinii pneumonia and eight patients who died had bacterial pneumonia at ICU admission. Univariate logistic regression analysis showed that patients with a low serum albumin levels and CD4 count, $P$. carinii pneumonia as the cause of respiratory failure, or a high APACHE II score on ICU entry, were at a higher risk for ICU mortality $(p=0.05$, table 3$)$. Likewise, the need for mechanical ventilation, the development of ARDS, and the appearance of metabolic acidosis (arterial $\mathrm{pH}$ $<7.35$ ) during ICU stay were factors associated with death. In the multivariate forward-selection logistic analysis, an APACHE II score $>17$ (odds ratio (OR) 4.9 (1.2-19.9), $\mathrm{p}=0.02)$, a serum albumin $<25 \mathrm{~g} \cdot \mathrm{L}^{-1}$ (OR 6.0 (1.3-27.1), $\mathrm{p}=0.01$ ), and $P$. carinii pneumonia diagnosis (OR $10.4(2.1-50.1), \mathrm{p}=0.003)$ remained as independent factors associated with death on ICU entry. Obviously, sicker patients required mechanical ventilation more frequently. Only one out of the 14 (7\%) patients with $P$. carinii pneumonia receiving mechanical ventilation was weaned successfully, compared with ten of the $18(55 \%)$ patients with bacterial pneumonia $(\mathrm{p}=0.007)$.

Table 3. - Factors influencing mortality in the intensive care unit (ICU)

\begin{tabular}{|c|c|c|}
\hline Risk factor & $\begin{array}{l}\text { Odds ratio } \\
(0.05-0.95 \mathrm{CI})\end{array}$ & $\begin{array}{l}\text { Univariate } \\
\text { p-value }\end{array}$ \\
\hline Age $>33$ yrs & $2.69(0.88-8.2)$ & 0.08 \\
\hline Prior antiretroviral therapy & $1.02(0.35-2.98)$ & 0.96 \\
\hline Prior HAART & $2.25(0.41-12.2)$ & 0.34 \\
\hline $\begin{array}{l}\text { AIDS diagnosis } \\
(\mathrm{A} 3, \mathrm{~B} 3, \mathrm{C} 3)\end{array}$ & $2.72(0.51-14.4)$ & 0.24 \\
\hline PCP diagnosis & $4.51(1.40-14.4)$ & 0.01 \\
\hline Corticosteroid therapy & $0.81(0.19-3.44)$ & 0.78 \\
\hline $\begin{array}{l}\text { MV requirement } \\
\text { during ICU stay }\end{array}$ & $19.2(3.8-96.4)$ & 0.0003 \\
\hline ARDS during ICU stay & $14.0(3.6-54.1)$ & 0.001 \\
\hline$P \mathrm{a}_{2} \mathrm{O}_{2} / F \mathrm{I}, \mathrm{O}_{2}<19 \mathrm{kPa}$ & $2.56(0.82-7.57)$ & 0.09 \\
\hline $\begin{array}{l}\text { Arterial pH }<7.35 \\
\text { during ICU stay }\end{array}$ & $3.62(0.81-9.82)$ & 0.05 \\
\hline APACHE II score $>17$ & $3.41(1.13-10.42)$ & 0.02 \\
\hline $\begin{array}{l}\text { CD4 lymphocytes } \\
<150 \cdot 10^{6} \cdot \mathrm{L}^{-1}\end{array}$ & $2.15(0.12-4.22)$ & 0.05 \\
\hline Serum $\mathrm{LDH}>1,000 \mathrm{IU} \cdot \mathrm{L}^{-1}$ & $1.34(0.45-3.99)$ & 0.59 \\
\hline Serum albumin $<25 \mathrm{~g} \cdot \mathrm{L}^{-1}$ & $3.06(0.96-9.5)$ & 0.05 \\
\hline
\end{tabular}

Data refer to ICU admission unless indicated otherwise. HAART: highly active antiretroviral therapy; AIDS: acquired immunodeficiency syndrome; PCP: Pneumocystis carinii pneumonia; MV: mechanical ventilation; ARDS: acute respiratory distress syndrome; $P \mathrm{a}, \mathrm{O}_{2}$ : arterial oxygen tension. $\mathrm{F}, \mathrm{O}_{2}$ : inspiratory oxygen fraction. APACHE II: acute physiology and chronic health evaluation score; $\mathrm{LDH}$ : lactate dehydrogenase. 
Only eight out of $21(38 \%)$ subjects with $P$. carinii pneumonia were discharged alive from ICU. Survivors had a lower APACHE II score (13.5 \pm 1.5 versus $18.0 \pm 1.2, \mathrm{p}=0.04)$ and less severe respiratory failure $\left(P \mathrm{a}, \mathrm{O}_{2} / F \mathrm{I}, \mathrm{O}_{2}\right.$ ratio: $23.7 \pm 3.8$ versus $15.0 \pm 1.9 \mathrm{kPa}, \mathrm{p}=$ $0.04)$ on ICU admission than nonsurvivors. Moreover, patients who died from $P$ carinii pneumonia showed a worse nutritional status ( $\mathrm{p}=0.03$ for albumin) and tended to show greater serum cholesterol values $(\mathrm{p}=$ 0.07) than survivors. In the multivariate stepwise regression analysis of these variables, the $\mathrm{Pa}, \mathrm{O}_{2} / \mathrm{FI}, \mathrm{O}_{2}$ ratio on ICU admission was the only factor related to ICU mortality by $P$. carinii pneumonia $(p=0.01)$. Bacterial co-infection, a very low CD4 count, and high serum LDH levels were not associated with increased mortality in these patients.

Regarding the patients bacterial pneumonia, those who died during their ICU stay $(n=8)$ were older (39.7 \pm 3.1 versus $31.5 \pm 1.6 \mathrm{yrs}, \mathrm{p}=0.04)$, had a lower CD4 count $\left(80 \pm 26\right.$ versus $\left.235 \pm 5210^{6} \cdot \mathrm{L}^{-1}, \mathrm{p}=0.01\right)$ and developed ARDS more frequently $(p=0.02)$ than survivors.
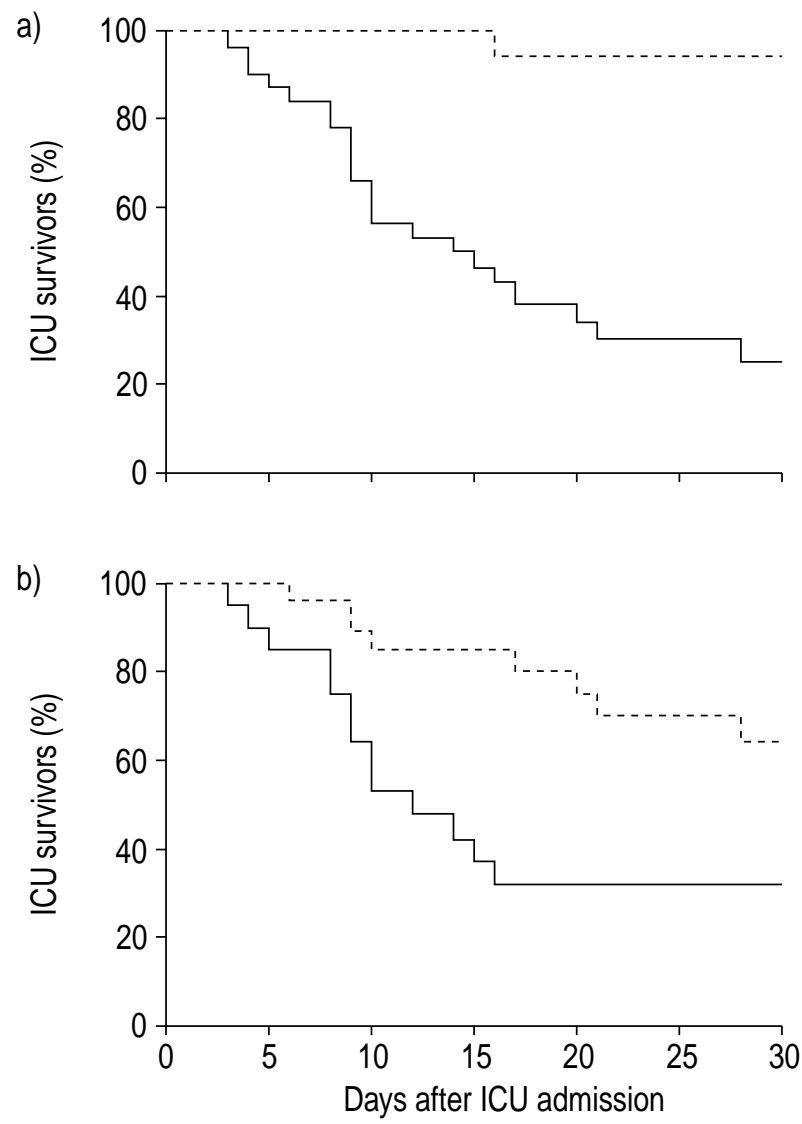

Fig. 2. - Kaplan-Meier estimates showed that a) survival was lower in human immunodeficiency virus patients that required mechanical ventilation $((\mathrm{MV} ;-) \log$ rank 20.2, $\mathrm{p}<0.001)$, with a median survival of 15 days since intensive care unit (ICU) admission compared with no MV (- -). Additionally, b) subjects with bacterial pneumonia (- -) had a better outcome than those with Pneumocystis carinii pneumonia (-) $(\log$ rank 8.2, $\mathrm{p}=$ $0.004)$. Patients with $P$. carinii pneumonia survived for a median period of 12 days after ICU entry. Follow-up truncated at 30 days because no deaths occurred in the ICU after this period.
Kaplan-Meier estimates showed that survival was associated with the need for mechanical ventilation (log-rank 20.2, $\mathrm{p}<0.001$ ), with a median survival of 15 days since ICU admission for ventilated patients (fig. 2). Moreover, subjects with bacterial pneumonia had a greater survival rate than patients with $P$. carinii pneumonia (log-rank 8.2, $\mathrm{p}=0.004)$. Patients with $P$. carinii pneumonia survived for a median period of 12 days after ICU entry (fig. 2).

\section{Follow-up of ICU survivors}

Thirty-four $(60 \%)$ patients were discharged alive from the ICU. However, three patients died in hospital within the week following ICU discharge and three more patients died within 10 days of leaving the hospital. Three patients had $P$. carinii pneumonia and one patient was from the bacterial pneumonia group. Death was due to other AIDS-related medical problems without respiratory involvement. The 28 patients that remained alive were followed for a median of 232 days (range, 15-968 days). The estimation of survival and outcome factors that influenced mortality were the same as those observed for ICU analysis (data not shown).

\section{Discussion}

In the present study a changing pattern in the aetiologies of life-threatening respiratory failure in HIV-infected patients admitted to the ICU was observed, with a decrease in the number of $P$. carinii pneumonia episodes compared with the previous decade. However, $P$. carinii pneumonia was still observed in people with unknown HIV infection and in those patients not compliant with the treatment or not undergoing prophylaxis. In addition, after the introduction of HAART, it was observed that few HIV patients with bacterial pneumonia were transferred to the ICU because of respiratory failure. The probability of survival was observed to be lower in cases of $P$. carinii compared to bacterial pneumonia, and in those subjects sick enough to require mechanical ventilation.

The aetiological pattern of life-threatening respiratory failure in HIV patients has evolved over the last few years $[8,9,21,22]$. As a consequence of the systematic use of prophylaxis against $P$. carinii and steroids as co-adjuvant treatment, the number and severity of $P$. carinii pneumonia seemed to decline in the early 1990s, whereas no reduction was observed in the cases of bacterial pneumonia admitted to ICU [5, $24]$. In the present study, only $6.8 \%$ of patients admitted to the authors' hospital because of $P$. carinii pneumonia required ICU admission, compared to $18.7 \%$ between 1986 and 1989 [23]. Moreover, P. carinii pneumonia was responsible for only $30 \%$ of the respiratory failures in HIV patients admitted to our ICU between 1993 and 1995 , compared to $67 \%$ observed in a previous survey (1985-1992) [2].

However, the immunological reconstitution caused by HAART may have again changed the aetiological pattern of respiratory failure in these patients after 1996 
$[7,10]$. In the present study a further decrease in the number of patients with $P$. carinii pneumonia admitted to hospital after 1996 was observed. Interestingly, the number of cases of bacterial pneumonia requiring intensive care also decreased drastically. The few cases of severe $P$. carinii and bacterial pneumonia admitted to ICU after 1996 mainly corresponded to patients newly diagnosed with AIDS, and those who were not compliant with HAART or the recommended prophylaxis regimens $[25,26]$. In addition, $P$. carinii prophylaxis may fail in cases with severe immunosuppression $\left(<50 \mathrm{CD} 4\right.$ cells $\left.\mu \mathrm{L}^{-1}\right)[14]$ or because of the development of $P$. carinii dihydropteroate synthase mutations, which may be responsible for some cotrimoxazole failures [27].

Microbiological identification was established in $40 \%$ of the cases of bacterial pneumonia, similar to our previous series [2]. Because BAL was not performed in seven patients, the incidence of cases of $P$. carinii pneumonia may have been underestimated. However, this was not plausible as these patients exhibited lobar infiltrates and did not receive treatment with cotrimoxazole, but survived. Pulmonary infection was community-acquired in 23 cases, and Streptococcus pneumoniae was the most frequently involved micro-organism, similar to reports in the general population [28, 29]. Although HIV-infection was not a risk factor for severe community-acquired pneumonia in a recent casecontrol study [30], bacterial pneumonia is reported to appear more frequently in HIV patients with less than 200 CD4 cells $\cdot \mu \mathrm{L}^{-1}$ [31]. Finally, M. tuberculosis infection was responsible for $7 \%$ of the ICU admissions, due to the high prevalence of tuberculosis in the Spanish HIV-infected population [32].

The clinical and epidemiological data observed in the present study are consistent with the literature [33]. Regarding radiographic findings, all patients with $P$. carinii pneumonia had bilateral interstitial infiltrates, while most of the bacterial pneumonia showed uni- and bilateral lobar infiltrates. APACHE II score, serum albumin level, and $P$. carinii pneumonia diagnosis were found as independent predictive factors of unfavorable outcome on ICU admission, in agreement with previous studies [2, 33, 34].

Due to the greater presence of patients with bacterial pneumonia, overall mortality of HIV-infected patients admitted to the ICU due to acute respiratory failure was $40 \%$, slightly lower than in the $1985-1992$ period $(55 \%)$ [2]. However, the prognosis of the few remaining severe patients with $P$. carinii pneumonia that enter in the ICU has not changed over the last decade [2]. The degree of respiratory failure on ICU admission remains as the main prognostic factor in these patients. In addition, some subjects with prior $P$. carinii pneumonia died early after ICU discharge, as a consequence of other AIDS-related problems, confirming the defective immunological status of this population. Similarly, ICU survival was related to the degree of immunosuppression in the patients with bacterial pneumonia, an observation that has also been reported in HIV patients with infective endocarditis [35].

The convenience of intensive care unit admission of human immunodeficiency virus-infected patients with life-threatening respiratory failure has been a matter of debate in many centres, due to the poor prognosis of these patients [36]. Although the total number of human immunodeficiency virus-patients that require intensive care has declined, survival improvement is still not detected in patients with Pneumocystis carinii pneumonia requiring mechanical ventilation. Better defining of predictive variables on hospital admission, absence of delay in diagnostic measures and improvement in non invasive support methods may have a role in future research. Finally, it is important to ascertain the past antiretroviral therapy of the subjects, because currently naive patients or those with only one or two antiretroviral failures may still be able to use the highly active antiretroviral therapy, which, on relieving their cellular immunosupression, may influence the morbidity and mortality in this population.

\section{References}

1. Gatell JM, Marrades R, El-Ebiary M, Torres A. Severe pulmonary infections in AIDS patients. Semin Respir Infec 1996; 11: 119-128.

2. Torres A, El-Ebiary M, Marrades R, et al. Aetiology and prognostic factors of patients with AIDS presenting life-threatening acute respiratory failure. Eur Respir J 1995; 8: 1922-1928.

3. 1995 revised guidelines for prophylaxis against Pneumocystis carinii pneumonia for children infected with or perinatally exposed to human immunodeficiency virus. National Pediatric and Family HIV Resource Center and National Center for Infectious Diseases, Centers for Disease Control and Prevention. Morb Mortal Wkly Rep 1995; 44: 1-11.

4. Hawley PH, Ronco JJ, Guillemi SA, et al. Decreasing frequency but worsening mortality of acute respiratory failure secondary to AIDS-related Pneumocystis carinii pneumonia. Chest 1994; 106: 1456-1459.

5. Gallant JE, Chaisson RE, Moore RD. The effect of adjuntive corticosteroids for the treatment of Pneumocystis carinii pneumonia on mortality and subsequent complications. Chest 1998; 114: 1258-1263.

6. Palella FJ, Delaney KM, Moorman AC, et al. Declining morbidity and mortality among patients with advanced human immunodeficiency virus infection. HIV outpatient study investigators. $N$ Engl J Med 1998; 338: 853-860.

7. Li TS, Tubiana R, Katlama C, Calvez V, Ait Mohand $\mathrm{H}$, Autran B. Long-lasting recovery in CD4 T-cell function and viral-load reduction after highly active antiretroviral therapy in advanced HIV-1 disease. Lancet 1998; 351: 1682-1686.

8. Wallace JM. HIV and the lung. Curr Opin Pulm Med 1998; 4: 135-141.

9. Curtis JR. ICU outcomes for patients with HIV infection. A moving target. Chest 1998; 113: 421-429.

10. Schneider MM, Borleffs JC, Stolk RP, Jaspers CA, Hoepelman AI. Discontinuation of prophylaxis for Pneumocystis carinii pneumonia in HIV-1-infected patients treated with highly active antiretroviral therapy. Lancet 1999; 353: 201-203.

11. Centers for Disease control and Prevention. 1993 revised classification system for HIV infection and surveillance case definition for AIDS among adolescents and adults. Morb Mortal Wkly Rep 1993; 41: 1 . 
12. American Thoracic Society. Hospital-acquired pneumonia in adults: Diagnosis, assessment, initial therapy, and prevention: A consensus statement. Am J Respir Crit Care Med 1996; 153: 1711-1725.

13. Bernard GR, Artigas A, Brigham KL, et al. The American-European consensus conference on ARDS: definitions, mechanisms, relevant outcomes, and clinical trial coordination. Am J Respir Crit Care Med 1994; 149: 818-824.

14. Murray JF, Matthay MA, Luce JM, Flick MR. An expanded definition of the adult respiratory distress syndrome. Am Rev Respir Dis 1988; 139: 720-723.

15. Knaus WA, Draper EA, Wagner DP, Zimmerman JE. APACHE II: A severity of disease classification system. Crit Care Med 1985; 13: 818-828.

16. American College of Chest Physicians/Society of Critical Care Medicine Consensus Conference Committee. Definitions of sepsis and organ failure and guidelines for the use of innovative therapies in sepsis. Chest 1992; 101: 1644-1655.

17. Vincent JL, Moreno R, Takala J, et al. The SOFA (Sepsis-related Organ Failure Assessment) score to describe organ dysfunction/failure. Intensive Care Med 1996; 22: 707-710.

18. Marshall JC, Cook DJ, Christou NV, Bernard GR, Sprung CL, Sibbald WJ. Multiple organ dysfunction score: a reliable, predictor of a complex clinical outcome. Crit Care Med 1995; 23: 1638-1652.

19. American Thoracic Society. Guidelines for the initial management of adults with community-acquired pneumonia: Diagnosis, assessment of severity, and initial antimicrobial therapy. Am Rev Respir Dis 1993; 148, 1418-1426.

20. Kaplan EL, Meier P. Non-parametric estimation for incomplete observations. J Am Stat Assoc 1958; 53: 457-481.

21. Rosen MJ, Clayton K, Schneider RF, et al. Intensive care of patients with HIV infection: utilization, critical care illnesses and outcomes. Pulmonary complications of HIV Infection Study Group. Am J Respir Crit Care Med 1997; 155: 67-71.

22. Lazard T, Retel O, Guidet B, Maury E, Valleron AJ, Offenstadt G. AIDS in a medical intensive care unit: immediate prognosis and long-term survival. JAMA 1996; 276: 1240-1245.

23. Fernandez P, Torres A, Miro JM, et al. Prognostic factors influencing the outcome in Pneumocystis carinii pneumonia in patients with AIDS. Thorax 1995; 50: 668-671.

24. Casalino E, Mendoza-Sassi G, Wolff M, et al. Predictors of short- and long-term survival in HIVinfected patients admitted to the ICU. Chest 1998; 113: 421-429.
25. Stoehr A, Arazsteh K, Staszewski S, et al. Pneumocystis carinii pneumonia in the Federal Republic of Germany in the era of changing antiretroviral therapy - IDKF 13 - German AIDS Study Group (GASG/ IdKF). Eur J Med Res 1999; 4: 131-134.

26. Moorman AC, Von Bargen JC, Palella FJ, Holmberg SD. Pneumocystis carinii pneumonia incidence and chemoprophylaxis failure in ambulatory HIV-infected patients. HIV outpatient study (HOPS) investigators. J Acquir Immune Defic Syndr Hum Retrovirol 1998; 19: 182-188.

27. Helweg-Larsen J, Benfield TL, Eugen-Olsen J, Lundgren JD, Lundgren B. Effects of mutations in Pneumocystis carinii dihydropteroate synthase gene on outcome of AIDS-associated $P$. carinii pneumonia. Lancet 1999; 354: 1347-1351.

28. Ruiz M, Ewig S, Marcos MA, et al. Etiology of community-acquired pneumonia in hospitalized patients: Impact of age, comorbidity and severity. Am J Respir Crit Care Med 1999; 160: 397-405.

29. Noskin GA, Glassroth J. Bacterial pneumonia associated with HIV-1 infection. Clin Chest Med 1996; 17: 713-723.

30. Ruiz M, Ewig S, Torres A, et al. Severe communityacquired pneumonia: risk factors and follow-up epidemiology. Am J Respir Crit Care Med 1999; 160: 923-929.

31. Hirschtick RE, Glassroth J, Jordan MC, et al. Hopewell PC. Bacterial pneumonia in persons infected with the human immunodeficiency virus. Pulmonary Complications of HIV Infection Study Group. $N$ Engl J Med 1995; 333: 845-851.

32. Buira E, Gatell JM, Zamora L, Mallolas J, Miro JM, Soriano E. Analysis of 1187 consecutive cases of AIDS: variations and trends in time. Enferm Infecc Microbiol Clin 1996; 14: 290-295.

33. Boldt MJ, Bai TR. Utility of lactate dehydrogenase $v s$ radiographic severity in the differential diagnosis of Pneumocystis carinii pneumonia. Chest 1997; 111: $1187-1192$.

34. Nickas G, Wachter RM. Outcomes of intensive care for patients with human immunodeficiency virus infection. Arch Intern Med 2000; 160: 541-547.

35. Ribera E , Mirû JM, Cortès E, et al. Influence of human immunodeficiency virus 1 infection and degree of immunosupression in the clinical characteristics and outcome of infective encodarditis in intravenous drug users. Arch Intern Med 1998; 158: 2043-2050.

36. Rogers PL, Lane C, Henderson DK, Parrillo J, Masur H. Admission of AIDS patients to a medical intensive care unit: Causes and outcome. Crit Care Med 1989; 17: $113-117$. 